\title{
Cytoplasmic inheritance and its effects on development and performance
}

\author{
L. C. Smith ${ }^{1}$ and A. A. Alcivar ${ }^{2}$ \\ 'Centre de Recherche en Reproduction Animale, Faculté de Médecine Vétérinaire, Université de \\ Montréal, Saint-Hyacinthe, QC J2S 7C6, Canada; and ${ }^{2}$ Department of Comparative Medicine, Tufts \\ University School of Veterinary Medicine, North Grafton, MA 01536, USA
}

In contrast to nuclear inheritance, cytoplasmic inheritance in mammals is derived mostly, if not exclusively, from the maternal line. Mitochondria, and their DNA molecules (mtDNA), are the genetic units of this method of inheritance. Mammalian mtDNA codes for 13 enzymes used in the mitochondrial energy-generating pathway, oxidative phosphorylation, 22 tRNAs and two rRNAs. Although all transcripts of mtDNA and their translational products remain in the mitochondria, most proteins used in mitochondria are from nuclear DNA and are imported after synthesis on cytoplasmic ribosomes. Spermatozoa introduce a small number of mitochondria into the cytoplasm of the egg at fertilization, which appear to be digested soon after penetration. Although the paternal contribution of mtDNA to the offspring is not believed to occur in mammals, some interspecific crosses have suggested that it does occur. Experiments with animals derived from reconstituted embryos, using nuclear or cytoplasmic transplantations, suggest that nuclearmitochondrial interactions are important but not essential in the survival and replication of exogenous mitochondria introduced into the egg. As the levels of heteroplasmy varied in several tissues of animals derived from reconstituted embryos, it is suggested that differential partitioning of mitochondria occurs during embryogenesis. Mitochondrial morphology changes substantially during oogenesis and throughout early cleavage stages. Somatic morphology and normal replication patterns are regained at the blastocyst stage. In pig oocytes and embryos, mitochondria aggregate and are closely associated with endoplasmic reticulum, lipid granules and large vesicles. Although the direct correlation of mitochondrial genes with reproductive traits is still unclear, some human degenerative diseases and performance traits in cattle can be related directly to specific mtDNA polymorphisms. In pigs, reciprocalcross comparisons have indicated greater offspring parent similarity with dam than sire for lean:fat ratio. A difference was also observed for oxygen consumption and oxidative phosphorylation, but not for anaerobic energy metabolism, in a pig reciprocal-cross experiment. Information on the transmission of mtDNA and its .effects on performance will have many implications not only for our understanding of mitochondrial genetics but also for the increased productivity of animals. There are also potential ramifications to the animal cloning industry.

\section{Introduction}

Traditional genetics assumes that, at fertilization, male and female gametes contribute an equal amount of genetic material to the offspring. Although development and performance of the offspring is generally 


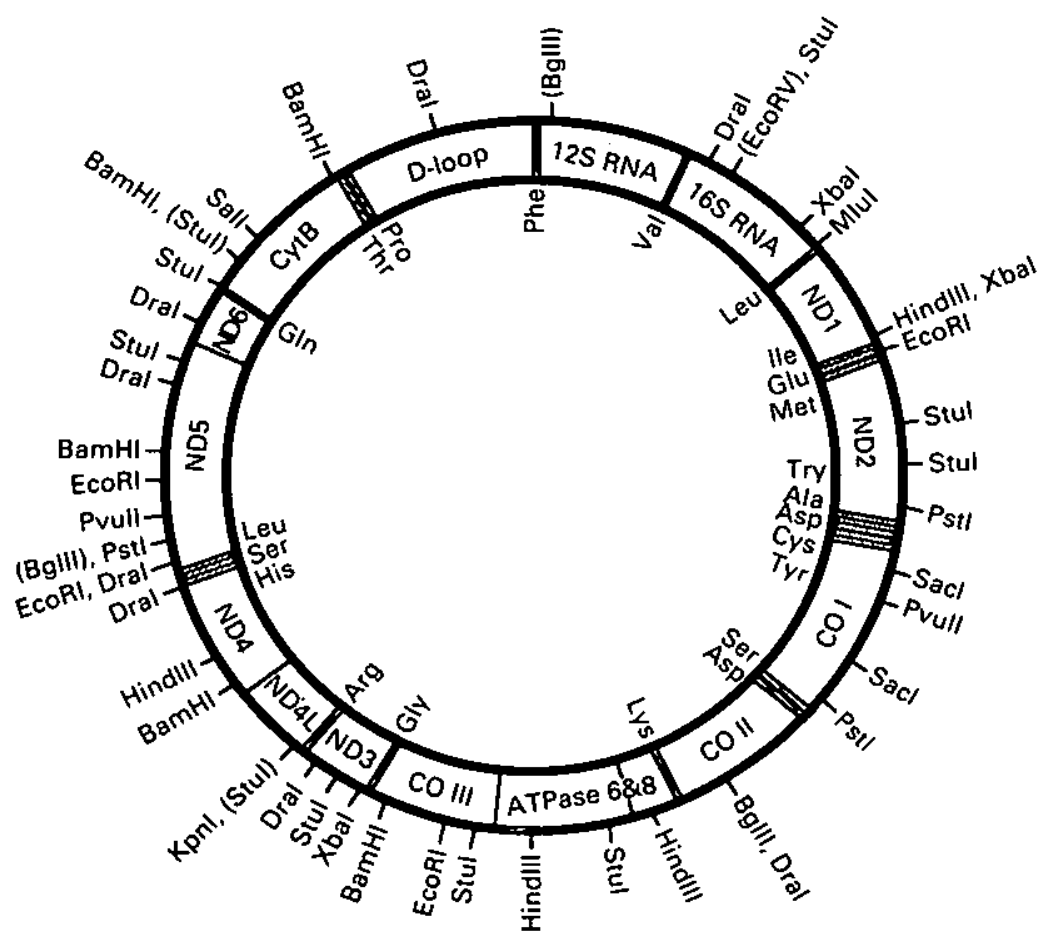

Fig. 1. Organization of pig mitochondrial DNA. mtDNA encodes seven subunits of the NADH-CoQ reductase complex (ND1, ND2, ND3, ND4L, ND4, ND5, ND6) ATPase subunits 6 and 8 (ATPase 6 and 8), cytochrome $c$ oxidase subunits 1,2 and 3 (COI, COII, COIII), and cytochrome $b$ (CytB). It also encodes for a small (12S RNA) and a large (16S RNA) ribosomal RNAs and 22 transfer RNAs (inner circle). No mammalian mtDNA genes contain introns. Restriction endonucleases in parentheses show the different polymorphic sites among breeds (based on data from Bibb et al., 1981; restriction map adapted from Watanabe et al., 1986).

believed to be due to additive, dominance or epistatic effects of genes contributed by both parents, other effects due to the differential imprinting of parental genes and the maternal effects on the pre- and perinatal environment in mammals further confound the contribution of each parent. These, however, are genetic effects derived from genes contained within the nucleus and transmitted via sexual reproduction. Mitochondria, cytoplasmic organelles which reproduce asexually, are the only known source of genetic material in the cytoplasm of mammalian cells and, therefore, provide an opportunity for an unbalanced contribution from each parent (maternal or cytoplasmic inheritance). We review herein the mechanisms of gene transmission by the mitochondrion and describe some of the experimental evidence for its effect on early development and performance in mammals. When available, specific references are made to work performed in pigs.

\section{The Mitochondrial Genome}

DNA is present in eukaryotes not only in the chromatin within the nucleus but also in some cytoplasmic organelles. Mammalian mitochondria, like the mitochondria of other kinds of eukaryotes, contain their own genome (Fig. 1). The mitochondrial DNA ( $m$ tDNA) is a closed circular molecule of approximately 16500 nucleotides which is located within the inner mitochondrial membrane (Shoffner and Wallace, 1990). Most somatic cells have hundreds of mitochondria and each carries thousands of mtDNAs (Shuster et al., 1988). The evolution of mitochondria has been the subject of continuing interest and considerable 
speculation since they were first recognized as cellular entities. Current molecular data strongly support an endosymbiotic origin of the mitochondrial genome from a direct common ancestor with purple bacteria (Gray, 1992), because the mitochondrion has an independent replication, transcription and translation system, which combines the features of prokaryotic and eukaryotic cells.

The mitochondrial energy-generating pathway, oxidative phosphorylation is composed of five enzyme complexes (Complexes $l$ to $V$ ) assembled from subunits derived from both mtDNA and nuclear DNA (nDNA). However, whereas most mtDNA genes encode subunits of the mitochondrial energygenerating pathway, the majority of these subunits are encoded by nDNA, translated in the cytosol and selectively imported into the mitochondrion (Shoffner and Wallace, 1990). Complex I of oxidative phosphorylation consists of approximately 39 polypeptides, seven (ND1, ND2, ND3, ND4L, ND4, ND5, ND6) encoded by mtDNA; complex II consists of four polypeptides, all nuclear; complex III consists of nine polypeptides, one (cytochrome $b$ ) encoded by the mtDNA; complex IV consists of 13 polypeptides, three (COI, COII and COIII) encoded by mtDNA; and complex V consists of 12 polypeptides, two (ATPase 6 and -8 ) encoded by the mtDNA. Apart from these 13 polypeptides, mtDNA encodes for the $12 \mathrm{~S}$ and $16 \mathrm{~S}$ ribosomal RNAs (rRNAs) and 22 transfer RNAs (tRNAs) involved in mitochondrial protein synthesis (Anderson et al., 1981; Shoffner and Wallace, 1990). Complete mitochondrial nucleotide sequences and gene contents have been determined for several mammals including humans, cows, mice and rats (Anderson et al., 1981, 1982a, b; Bibb et al., 1981; Gadaleta et al., 1989).

Partial sequence information has been obtained by restriction site mapping of mtDNA obtained from the kidney of several breeds of European and Asian pigs (Watanabe et al., 1985; Watanabe et al., 1986). Authors reported a restriction endonuclease cleavage map using 18 enzymes which recognize six nucleotides and one four-nucleotide-recognizing enzyme (Fig. 1). Detailed sequence information is also available for a 237 nucleotide pair (np) region enclosing part of the genes for ATPase8, ATPase6 and COIII (Watanabe et al., 1986). Within this region there was a $19.8 \%, 25.7 \%, 19.4 \%$ and $21.5 \%$ sequence difference with the same regions of cow, human, mouse and rat mtDNA, respectively. A comparison was also performed among several breeds of pig and Japanese wild boars based on their restriction endonuclease cleavage patterns (Watanabe $e t$ al., 1985). Some mtDNA polymorphisms were observed in the cleavage patterns with Bglll, EcoRV, Sacl, Stul and Taql. Two distinct types of restriction pattern were observed. First, the restriction patterns of Landrace, Hampshire, Duroc, Pitman-Moore and one Large White group were similar and were classified as European type. Second, the patterns of another Large White group, the miniature pigs Ohmini and Gottingen, Taiwan native breeds, and Japanese wild boars were similar, and were grouped as the Asian type. The estimated percentage difference between the European and Asian breeds is $1.75 \%$, which according to evolutionary theory translates into a separation of parent stocks of about $0.8-0.9$ million years ago (Watanabe et al., 1986). Analysis of mtDNA with Hinfl and HaelI showed that samples derived from pigs of the Hampshire breed exhibited patterns similar to the Asian (Gottingen minipig) type (Hecht, 1990). These results suggest that both the Gottingen minipig and the Large White breed represent maternal lineages both of European and Asian origin. Moreover, among the European pig breeds, two variable sites have been detected: one in a Duroc and another in the Belgian Landrace, using EcoRV and Hincll enzymes, respectively (Hecht, 1990).

\section{Mitochondrial Inheritance}

For many years, it has been assumed that mitochondrial genes, in contrast to genes in the nucleus, have an exclusively maternal mode of inheritance in mammals (Hutchinson et al., 1974; Giles et al., 1980; Hayashi et al., 1983; Gyllensten et al., 1985). The predominance of mitochondria of maternal origin in the offspring can be partially explained by the fact that at fertilization the spermatozoon contains approximately 75 mitochondria (Bahr and Engler, 1970; DeMartino et al., 1979; Hecht et al., 1984) compared with approximately 100000 mitochondria in the ooplasm in mice and cows (Piko and Matsumoto, 1976; Michaels et al., 1982; Gyllensten et al., 1985). Thus there is a 1:1000 ratio between paternal and maternal mtDNA molecules. However, use of a more sensitive test of paternal contribution, an interspecific backcross study between Mus spretus and Mus domesticus showed paternal transmission of mtDNA at a ratio of approximately 1:50 000 per generation (Gyllensten et al., 1991) which is 50 times lower than expected if paternal and maternal mitochondria had equal abilities to survive and replicate throughout development. This 
contrasts with a more recent finding involving intra- and interspecific crosses of the marine mussel Mytilus, showing a paternal mtDNA contribution of 1:10 (Zouros et al., 1992). It is unclear whether paternal transmission of mtDNA occurs at any level in mammals, and the mechanism by which most or all sperm mitochondria become inactive is unknown.

Mitochondria from the sperm tail constituents have been shown by ultrastructural studies to be carried into the oocyte at fertilization (Szöllösi, 1965; Hiraoka and Hirao, 1988). One possible mechanism for matemal inheritance of mtDNA is the capacity of the oocyte to recognize paternal mitochondria and eliminate them as foreign organelles. This view is supported by studies in hamsters showing that sperm mitochondria are enclosed by multivesicular bodies after fertilization and later digested into small molecular elements during the two-cell stage of development (Hiraoka and Hirao, 1988). Other studies of sea urchin eggs and embryos have shown that the structure and metabolic activity of the patemal mitochondrion begins to degenerate soon after the first cell cycle division of the zygote (Anderson and Perotti, 1975).

Maternal inheritance of chloroplast DNA in higher plants is believed to be governed by methylation of specific DNA sites on the maternal organelle, which protects it from degradation in the zygote (Sager and Grabowy, 1983). Mitochondrial morphology varies during spermiogenesis (DeMartino et al., 1979) and it has been proposed that mitochondria may also be altered and possibly debilitated during spermiogenesis (Vaughn et al., 1980). However, an extensive study in CD1 mice showed no difference in the state of methylation of mtDNA among oocytes, spermatozoa and earlier testicular cell types (Hecht et al., 1984) and between germinal and somatic cells of rats (Alcivar et al., 1992). Moreover, no loss, amplification, or translocation of sizeable regions of the mitochondrial genome could be detected at different stages of spermiogenesis, suggesting that maternal inheritance is not mediated by alteration of the paternal mtDNA (Hecht et al., 1984). The mtDNA present in spermatozoa is also known to transcribe mitochondrial ribosomal and messenger RNAs, suggesting that, at least at the time of fertilization, the paternal mitochondria are likely to be translationally competent (Alcivar et al., 1989).

\section{Mitochondria in Animals Derived from Reconstituted Embryos}

Direct microinjection of mitochondria isolated from testis or liver into the cytoplasm of mouse zygotes has been performed to assess their ability to survive and proliferate in the developing embryo (Ebert et al., 1989). Although microinjection caused no apparent detriment to the survival and viability of the embryos, no exogenous mtDNA could be detected in fetal samples or tissues from the mature progeny suggesting that the 'foreign' mitochondria have the same fate during early embryogenesis as the mitochondria of the spermatozoon. This result contrasts with the findings of low levels of paternal miDNA in mouse interspecific crosses (Gyllensten et al., 1991). Moreover, recent data indicate that there are high levels of mitochondrial heteroplasmy in progeny derived from reconstituted embryos of mice and cows (Smith et al., 1991; Plante et al., 1992). In mice, both karyoplast (nucleus and cytoplasm) and cytoplast (cytoplasm) transplantations have been performed between strains carrying Mus domesticus (Md) and Mus molossinus (Mm) mitochondria. Embryos containing $\mathrm{Mm}$ mitochondria were obtained after four generations of backcrossing pure $\mathrm{Mm}$ females to $\mathrm{C} 57 \mathrm{BI} / 6(\mathrm{Md})$ males. Although $97 \%$ of the nuclear genes were of Md origin, they contained exclusively Mm mitochondria, as detected by our Southern and PCR protocols for mtDNA. A $1.6 \mathrm{~kb}$ segment of mtDNA containing restriction fragment length polymorphism (RFLP) for Md and Mm was amplified from total tail DNA samples of the reconstituted progeny. PCR primers were based on sequences reported by Bibb et al. (1981). Although only one kind of mtDNA was detected in all animals derived from embryos with reconstituted cytoplast, animals derived from embryos with reconstituted karyoplast showed various degrees of mtDNA heteroplasmy (Fig. 2). Since at least twice the amount of 'foreign' mitochondria is transferred to the host zygote during cytoplast reconstitution compared with that in karyoplasts, these results suggest that nuclei preferentially replicate mitochondria of their own species. This result can be interpreted as an explanation for the high levels of heteroplasmy in the karyoplast group.

Other experimental approaches have been used for introducing mitochondrial genes into mice. Teratocarcinoma stem cells were successfully used to introduce mtDNA mutants into mouse blastocysts to create mosaic animals (Watanabe et al., 1978). Some degree of mtDNA sequence variation has been 
EcoRI

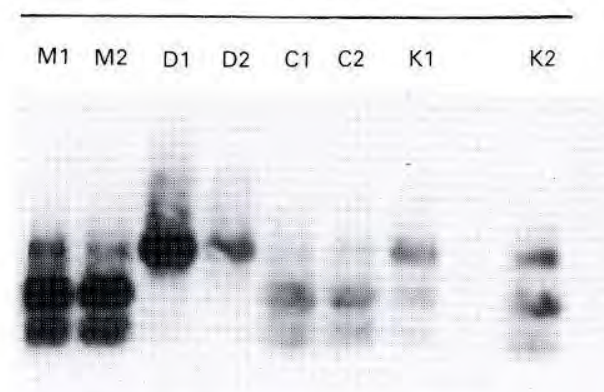

HindIII

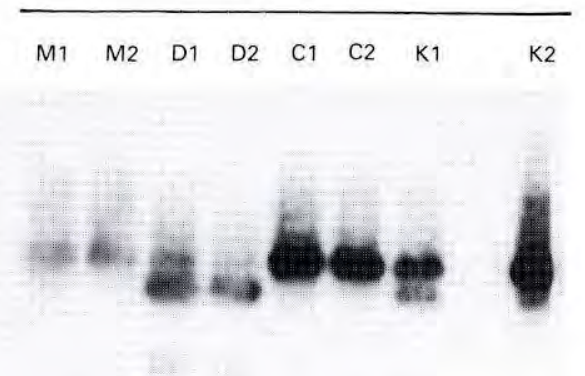

Fig. 2. Analysis of tail mtDNA patterns in control animals and animals derived from embryos with reconstituted cytoplast and karyoplast. PCR products from the amplification of a $1.64 \mathrm{~kb}$ fragment of mtDNA contain the genes for ATPase6, COIII, tRNAGly and the first 80 bases at the $3^{\prime}$ end of the ND3 gene. Oligonucleotide primers were designed on the basis of the sequence for Mus domesticus (Bibb et al., 1981). Amplified fragments were digested with either EcoRI or HindIII. Digestion products were run on a 1\% agarose gel and transferred by Southern blotting to a nylon membrane and hybridized with a clone containing part of the Mus molossinus mtDNA (Ebert et al., 1989; Alcivar et al., 1989). M1 and M2: Mus molossinus; D1 and D2: Mus domesticus; $\mathrm{C} 1$ and $\mathrm{C} 2$ : animals derived from embryos with reconstituted cytoplast; $\mathrm{K} 1$ and $\mathrm{K} 2$ : animals derived from embryos with reconstituted karyoplast.

observed in bulls derived from a single embryo by nuclear transplantation (Plante et al., 1992). Although it was not possible to trace the polymorphism to the host oocytes used in the reconstitution of embryos, it is likely that, as for mice, the mtDNA from the oocyte will be present in different proportions in many tissues of the cloned adult animals. As these were bulls, germ-line transmission of mtDNA to the progeny is unlikely. However, when cows are produced by cloning, the source of host oocytes should be considered to match beneficial nuclear and cytoplasmic genes. It should be noted, however, that mtDNA heteroplasmy has also been reported under normal conditions in many mammals including cattle (Hauswirth and Laipis, 1985; Ron et al., 1992), rabbits (Hecht, 1990) and Mus musculus (Boursot et al., 1987). In dairy cows, heteroplasmy was observed in the mitochondrial ND5 gene and D-loop region in individual animals of one lineage of Holstein cows, and mitochondrial DNA chimaerism was found in heart, liver and brain, suggesting that mtDNA segregation occurs early in embryogenesis (Hauswirth and Laipis, 1985). In Yorkshire pigs, however, hybridization analyses of the mtDNA from liver, testis, blood, brain, ovary, kidney and heart digested with EcoRI and other restriction endonucleases have shown no difference in the mtDNA patterns of the male and female tissues examined (A. A. Alcivar, unpublished results).

Further analysis of the mtDNA content of mice derived from karyoplast transplantations in several organs indicated different levels of heteroplasmy (Fig. 3) (Smith et al., 1992). Using Southern blot analysis of SpeI digested total DNA hybridized with a whole mtDNA mouse probe cloned in our laboratory, all animals analysed contained, at least in a few tissues, mtDNA of both $\mathrm{Mm}$ and $\mathrm{Md}$ origin. One animal contained Mm mtDNA in all organs and tissues examined (brain, heart, muscle, kidney, liver, spleen, colon, pancreas, bladder and testis) plus a considerable amount of Md mtDNA in brain and spleen. Another animal contained Md mtDNA in all tissues and organs analysed (brain, lung, liver, spleen, colon and bladder) and a small amount of Mm mtDNA could be detected in brain, spleen and colon. Moreover, we determined that one out of four animals derived from cytoplast reconstituted embryos was found to contain Mm and Md mtDNA in brain and heart, whereas other tissues and organs (muscle, kidney, lung, liver, spleen and stomach) contained only Mm mtDNA at our level of detection (Fig. 4). The results demonstrate that mtDNA from karyoplast and occasionally also from cytoplast transplanted zygotes proliferates in the embryo throughout development and can be detected in several tissues of the adult animal. The degree of heteroplasmy varies among tissues in both karyoplasts and cytoplasts, which suggests differential partitioning of mitochondria during development. The brain was more commonly 


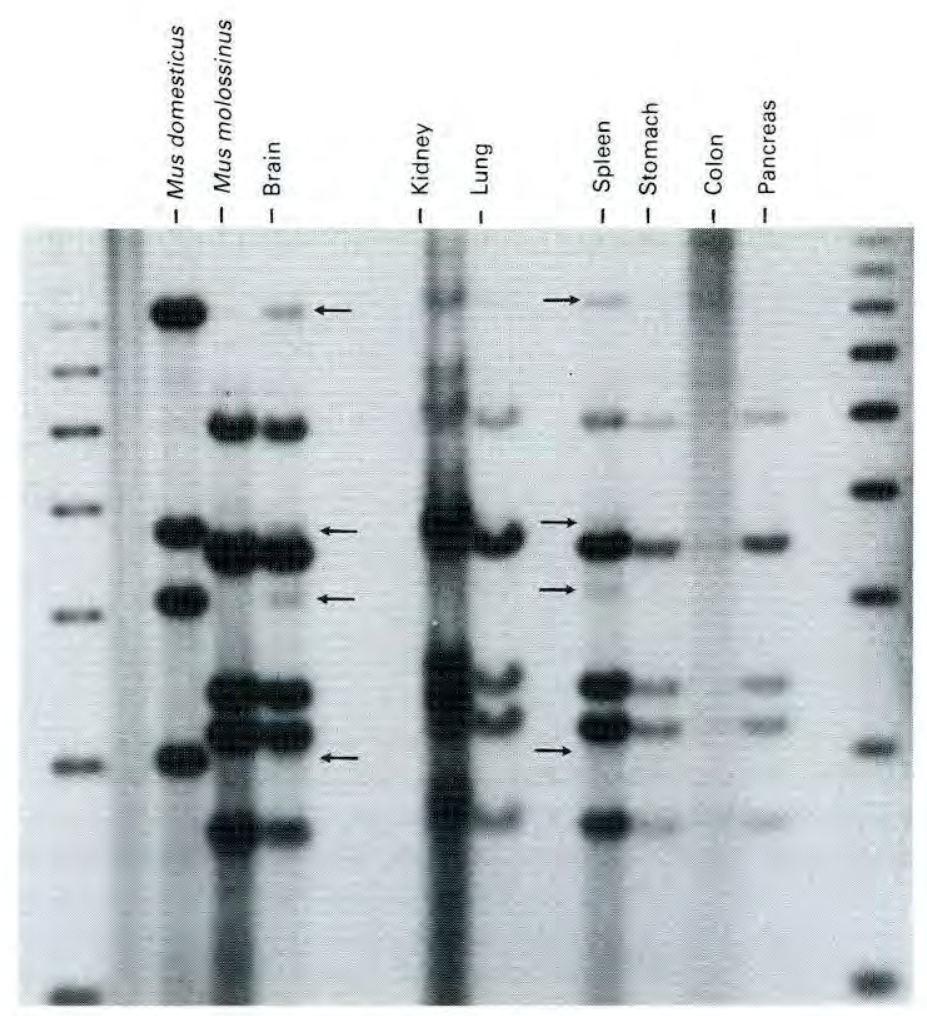

Fig. 3. Analysis of mtDNA content in several tissues from animals derived from embryos with reconstituted karyoplast. This animal was derived from an embryo produced by fusing a Mus domesticus karyoplast to an enucleated zygote containing Mus molossinus mitochondria. Total DNA was extracted from several tissues and digested overnight with SpeI at $37^{\circ} \mathrm{C}$. Digestion products were run on a $1 \%$ agarose gel and transferred by Southern blotting to a nylon membrane. The mtDNA was detected by hybridization with a nick-translated probe containing the entire mitochondrial genome extracted from the liver of a New Zealand black mouse (Mus domesticus). The mtDNA was cut with BamHI into two fragments and cloned using the vector Bluescript (Promega, Madison, WI). One clone (NZB7) contained a fragment spanning the region from nucleotide 11068 to 3572 , whereas a second (NZB10) consisted of nucleotide 3572 to 11068 (nucleotide position based on sequence by Bibb et al., 1981). Arrows indicate RFLP characteristic of Mus domesticus mtDNA in a Mus molossinus dominated mtDNA RFLP pattern.

heteroplasmic than were other tissues analysed, followed by the heart and spleen which were heteroplasmic in two animals.

\section{Mitochondria During Early Development}

Ultrastructural studies have shown that large numbers of mitochondria of differing size and morphology appear during the period from oogenesis to early embryogenesis in mammals (Szöllösi, 1972; Piko and Matsumoto, 1976; Beerman and Hansmann, 1986). Meiotic maturation of the oocyte is accompanied by translocations of mitochondria to the perinuclear region during formation of the meiotic spindle. It has been suggested that this movement enables mitochondrial sequestration to areas that require high 


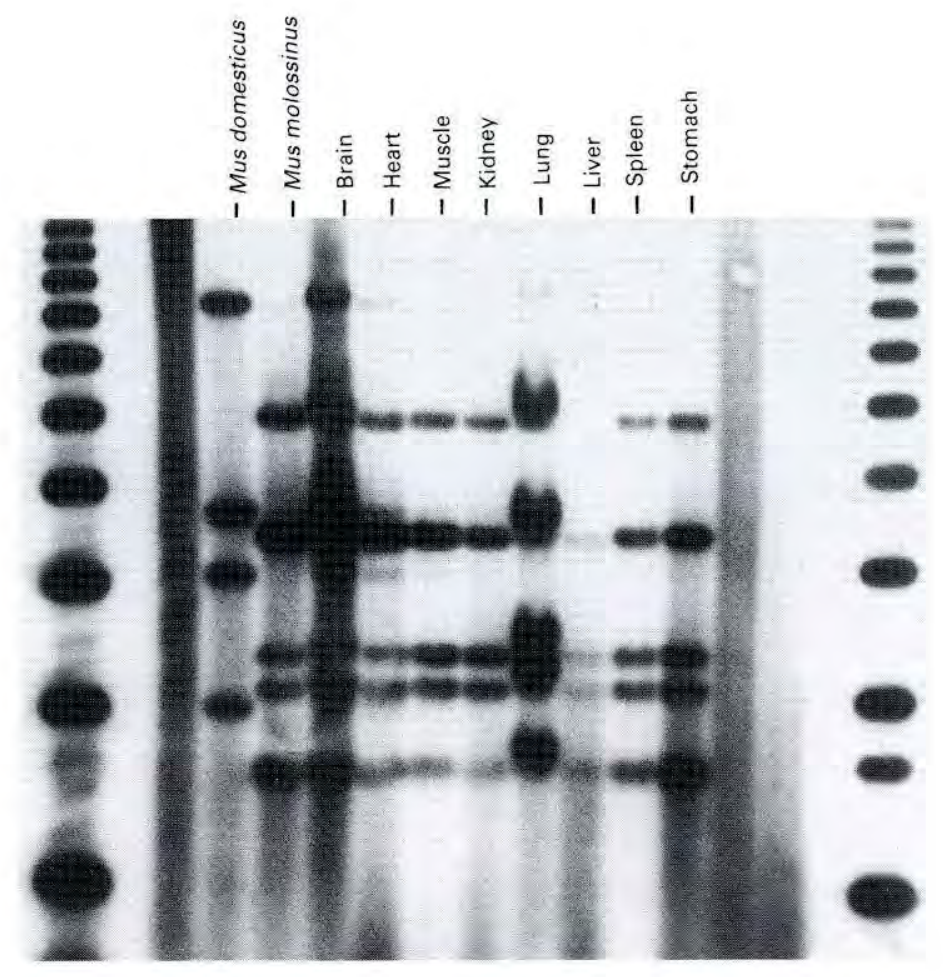

Fig. 4. Analysis of mtDNA patterns in several tissues from animals derived from embryos with reconstituted cytoplast. This animal was derived from an embryo produced by fusing a Mus domesticus cytoplast to a zygote containing Mus molossinus mitochondria. Total DNA was extracted from several tissues and digested overnight with SpeI at $37^{\circ} \mathrm{C}$. Digestion products were run on a $1 \%$ agarose gel and transferred by Southern blotting to a nylon membrane. The mtDNA was detected by hybridization with a nicktranslated probe containing the entire mitochondrial genome extracted from the liver of a New Zealand black mouse (Mus domesticus). Although Mus molossinus mtDNA is present in all tissues, Mus domesticus mtDNA sequences can be seen in brain and heart.

concentrations of ATP (Van Blerkom and Runner, 1984). During mouse preimplantation development, mitochondria undergo structural differentiation from a condensed, vacuolated appearance, with concentric cristae in late stage oocytes and early cleavage embryos, to become elongated with more numerous and predominantly transversely arranged cristae during development from the four- to eight-cell stage through the blastocyst stage (Stern et al., 1971; Piko and Matsumoto, 1976; Wassarman and Josefowicz, 1978). In spite of these changes, however, mtDNA replication does not occur during early embryogenesis as the number of mtDNA molecules per embryo remains the same from the one-cell to blastocyst stage (Piko and Taylor, 1987).

In cattle, the number of mitochondria increases more than one hundred times during the period of oocyte growth to reach 136000 mitochondria in the mature preovulatory oocyte (Hauswirth and Laipis, 1985). This value compares with an average of 92500 mitochondria found in mouse eggs (Piko and Matsumoto, 1976). The increase in number of mitochondria is proportional to the increase in cytoplasmic volume, which may indicate that oocytes require a fixed amount of functional mitochondria per unit volume of cytoplasm to remain viable. Moreover, the mtDNA copy number appears to correlate with 
oocyte volume since the amount of mtDNA per cell increased from about $0.1 \mathrm{pg}$ in primordial cells to $4.5 \mathrm{pg}$ (260 000 molecules) in bovine preovulatory eggs (Hauswirth and Laipis, 1985). The mitochondrial distribution in bovine oocytes has been associated with the hormonal patterns of both gonadotrophins and steroids (Kruip et al., 1983; Hyttel et al., 1986).

In pigs, during the period immediately following germinal vesicle breakdown, the number of mitochondria is reduced by two-thirds with a concomitant and proportional $300 \%$ increase in individual mean mitochondrial volume (Cran, 1985). Whereas some degeneration takes place during the period, it has been suggested that this decline in the number of mitochondria is due to fusion between mitochondria. Although mitochondria are highly concentrated in the area close to the plasma membrane before germinal vesicle breakdown, no such concentrations are observed immediately before ovulation. However, mitochondria of oocytes, zygotes and early embryos tend to occur in small groups or aggregates, which are not seen in cells of the trophoblast or of the inner cell mass in blastocysts. These mitochondrial aggregates are closely associated with endoplasmic reticulum, lipid granules and large vesicles. A recent report using a three-dimensional reconstruction of mitochondria with the aid of a computer graphics program indicates that most aggregates consist of two or three mitochondria rather than several, and that most are irregular in shape (Krause et al., 1992). It is interesting to note that both biochemical and structural differences have been observed between ovarian mitochondria from follicular and luteal stages of pigs (Campbell et al., 1980). The drastic changes in mitochondria observed during growth and differentiation of pig Graafian follicles were accompanied by differential expression of mitochondrial genes, and were influenced by LH (Campbell et al., 1980; Rowe et al., 1981; Rowe and Bremm, 1989).

In other species, however, mitochondria are dispersed throughout the cells during early development. In mice, mitochondria in normal cleaving embryos in vitro and in vivo were found to be homogeneously distributed throughout the cytoplasm of the blastomeres during interphase. In embryos in which development is arrested in vitro, the mitochondria become progressively aggregated and localized in the perinuclear region and the area of the cytocortex immediately adjacent to the plasma membrane. Specific translocations to the mitotic spindle were observed during cleavage suggesting that mitochondrial migration is a prerequisite for normal cleavage (Muggleton-Harris and Brown, 1988). Similar results were found when we used Mus domesticus zygotes; the mitochondria were found closely associated with pronuclei and the surrounding cytoskeleton (Fig. 5b), but addition of cytoskeletal inhibitors gave a pattern of mitochondrial dispersal (Fig. 5d) (L. C. Smith, unpublished data).

These early nucleo-mitochondrial interactions may also be responsible for the incompatibility found in interspecific nuclear transplantations with mouse zygotes (Smith et al., 1991). Zygote-derived exogenous mitochondria injected into zygotes through cytoplast transplantation did not interfere with the development of embryos to the blastocyst stage. This is not the case with karyoplast-transplanted zygotes. As expected, the transplantation of karyoplasts from the Mm zygotes, which contain a $97 \%$ Md nucleus due to four generation backcross to Md males, to Md-enucleated zygotes did not interfere with development. However, Md karyoplasts transplanted to enucleated zygotes containing mitochondria of $\mathrm{Mm}$ origin failed to develop normally in many cases suggesting nuclear-mitochondrial incompatibility. Although fewer blastocysts were obtained from this reconstituted group, no apparent difference was found in their ability to undergo successful gestation (L. C. Smith, unpublished). Similar incompatibility has been observed after reconstitutions between Mus musculus and Mus caroli (Solter et al., 1985). As in the latter case, the inability of these interspecific nuclear transplanted embryos to develop did not result from the simultaneous transfer of membrane or small amount of cytoplasm in the pronuclear karyoplast, as control embryos that received only interspecific membrane-bound cytoplasm did develop to term. Taken together, these results suggest that a threshold proportion of exogenous mitochondria is required to cause this interspecific nuclear-cytoplasmic incompatibility for early embryonic development. It should be noted, however, that in mice and rats, under normal breeding or embryo transfer conditions, differences in mtDNA between donors and recipients do not affect pregnancy rates (Fisher-Lindahl and Burki, 1982; Alcivar and Pineda, 1990). The percentage survival to weaning, however, was significantly affected by the mtDNA composition of the embryo under embryo transfer conditions only, and may be related to differences in the levels of mitochondrial COII and ATPase6 mRNA between type A and B rats (Alcivar and Pineda, 1990; Alcivar et al., 1992). 


\section{Cytoplasmic Inheritance, Mitochondria and Performance}

The genetic component of performance of domestic animals is generally assumed to be under the control of many additive direct genes each of small effect, and rarely includes other aspects such as dominance, epistatic, and maternal genetic effects. Maternal genetic influences on performance may originate from specific imprinting of maternal nuclear genes or from genes stored in the cytoplasm of the oocyte, that is mtDNA. However, maternal genetic effects may not be transmitted exclusively through DNA but also through cytoplasmic determinants stored in the oocyte that interact with the embryo later in development, that is the $o$ allele in amphibians (Brothers, 1976), or environmental effects brought about either by the uterus during gestation or by the postnatal environment, that is milk, which may modify gene expression in the progeny.

Although recent evidence points to the effects of maternal lineages (i.e. cytoplasmic inheritance) on production traits of economic significance in livestock animals (Bell et al., 1985; Hiendleder et al., 1991; Schultz et al., 1992), the effects of cytoplasmic inheritance are not well understood. Bell et al. (1985) used 4461 cows in 102 cytoplasmic lineages to show that $2 \%$ of the variation in milk yield, $1.8 \%$ of the variation in fat yield, and $3.5 \%$ of the variation in percentage of fat could be explained by cytoplasmic lineages. In another study, $10 \%$ of the variation in milk, fat and protein production and $13 \%$ of the variation in economic returns of milk have been attributed to cytoplasmic components (Huizinga et al., 1986). In a recent study of 38 different maternal lineages, variations in the mtDNA were found (Schultz et al., 1992). The effects of the maternal lineages on production and reproduction traits were examined by statistically partitioning nuclear and cytoplasmic effects using 17 of the most common bovine mtDNA polymorphic lineages (Schultz et al., 1992). Cytoplasmic effects also accounted for significant differences in reproductive traits, such as time to conception, which accounted for additional reproductive and health costs (Freeman and Beitz, 1992). Most of the mtDNA changes in cows within different maternal lineages are due to mutations in the D-loop - a non-coding region where transcriptional promoters of both the light and heavy strands of mtDNA are located (Upholt and Dawid, 1977; Hauswirth and Laipis, 1985). In sheep, mtDNA sequence variability also occurs in the D-loop, but changes in other regions of the mtDNA such as those coding for cytochrome $b$, COIII, ATPase 6 and ND5 genes also occur (Hiendleder et al., 1991). The types of mtDNA were shown to influence the birth weight and weight of lamb per ewe per birth significantly, but mtDNA affected neither the activity of some mitochondrial enzymes nor oxygen consumption in these animals (Hiendleder et al., 1991).

As mentioned earlier, heterogeneity of mtDNA sequences has been shown among many mammals and there are occasional variations within maternal lineages. The direct effect of the mitochondrial locus on economic traits (mtETL) can be determined by comparing the mean trait values of maternal lineages with differing alleles for a mitochondrial RFLP (mtRFLP) (Ron et al., 1992). Since progeny of a single maternal lineage are expected to have the same mitochondrial allele unless an mtDNA mutation has occurred, it is sufficient to determine the genotype of only a few individuals per lineage and to use the records between lineages to determine the effect of the mtRFLP on the mtETL. A study of dairy cattle using the mtRFLP of 67 maternal lineages divided into four milk production groups demonstrated that the distribution of rare alleles was not random across groups and among lineages, indicating a possible relationship between these polymorphisms and milk production (Ron et al., 1992). The authors concluded that by choosing individuals with extreme phenotypes for genotyping (selective genotyping) and at least ten recorded animals per lineage, an mtDNA locus with an effect of 0.25 standard deviations could be detected by genotyping two to three individuals of each of 120 maternal lineages.

In contrast to the molecular approach, variation in mitochondrial genes affecting productivity may be measured in terms of their effects on cellular energy metabolism. A crossbreeding experiment between German Landrace (GL) and German Yorkshire (GY) pigs was carried out to verify the effects of the cytoplasm on heterosis. A significant positive heterosis and reciprocal-cross difference for lean:fat ratio with greater offspring-parent similarity to the dam than to the sire was observed (Dzapo et al., 1983). This was taken to indicate a probable effect of extrachromosomal inheritance on fat deposition. Whereas a strong heterotic effect was found for reproductive performance ( $12 \%$ more piglets per year), litter sizes were approximately equal between reciprocal crosses. The relationship of the heterotic effect with mitochondria was assessed by metabolic measurements in heart, liver and scrotal tissue at different ages 

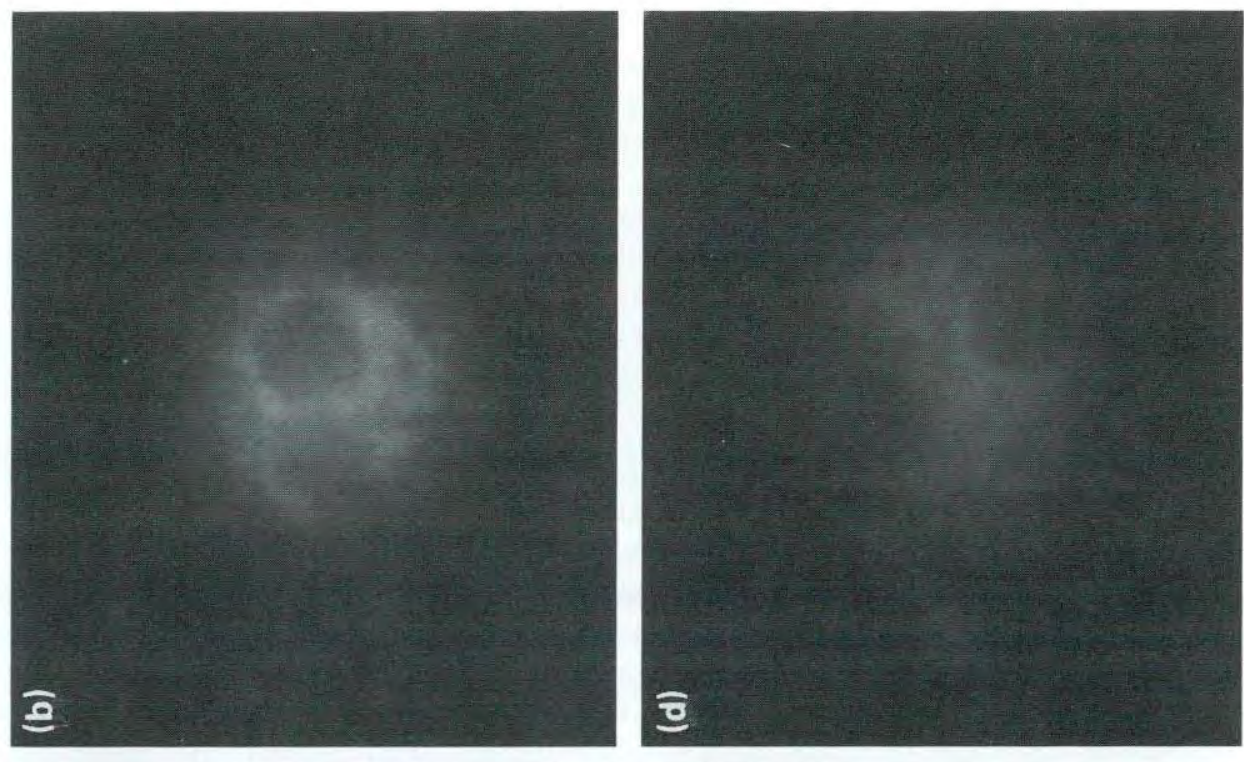

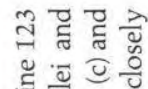

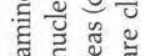

ช็

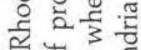

范客

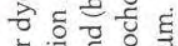

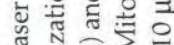

तै ॠ

트을

पु

उ. $\frac{1}{5}$ 嵌

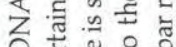

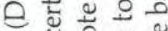

ᄀ 워

m० ते कू क

mे 웅 웅

点至

टै ठ요

ㅇำ

จ

ช 들

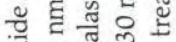

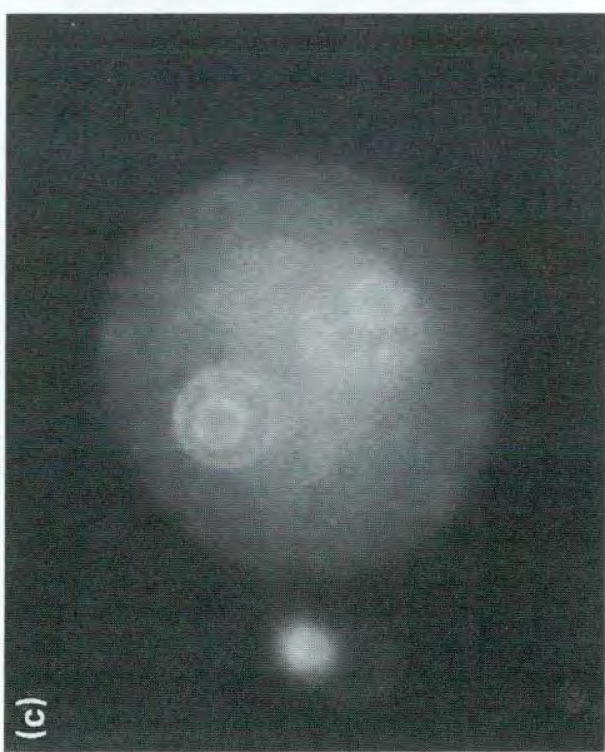

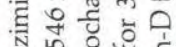

든

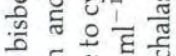

๘ छ

능

उ

둰도

추ㅇㅝㅠ

룰 듇

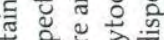

के

ఖ 니요

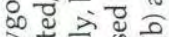

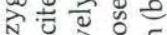

y $x: \frac{1}{x}: 5$

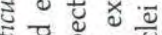

क्ष

홍

政

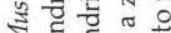

২. 당

in -

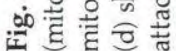


(Dzapo and Wassmuth, 1983). Oxygen consumption and oxidative phosphorylation differed significantly between reciprocal crossbreeds in some cases, tending towards the dam breed rather than the sire breed. It was suggested that mitochondrial energy metabolism can act as a metabolic indicator of the interaction of nuclear and mitochondrial genes which result from the crossbreeding and its consequent heterosis. It is proposed that heterosis in mitochondrial energy metabolism may stimulate additional heterosis for carcass fat and reproductive traits (Dzapo and Wassmuth, 1983). Finally, reciprocal crosses showed small to medium heterosis for aerobic enzyme activity in liver mitochondria and large heterosis in enzyme activity in scrotal mitochondria. No heterosis was found for anaerobic energy metabolism. The results clearly showed that oxidative energy metabolism in the mitochondria is one of the most important manifestations of heterosis in cell physiology and that interactions between chromosomal and mitochondrial genes play an important role in the expression of this heterosis (Dzapo and Wassmuth, 1984).

Since the mtDNA genes are either subunits of oxidative phosphorylation enzymes or the structural RNAs necessary for their expression, deleterious mtDNA mutations invariably result in deficiencies in mitochondrial energy metabolism. Several mtDNA mutations that cause human degenerative diseases have been identified in recent years. The mtDNA disease mutations that have been described to date fall into four groups: missense mutations, protein synthesis mutations, insertion-deletion mutations and copy number mutations (Wallace, 1992). These mutations are associated with a broad spectrum of clinical manifestations, including blindness, deafness, dementia, movement disorders, weakness, cardiac failure, diabetes, renal dysfunction and liver disease. Organs and tissues rely differently on oxidative phosphorylation and, therefore, as mitochondrial ATP production declines, it successively falls below the minimum energetic levels necessary for each organ to function normally. This results in a progressive increase in the number and severity of clinical symptoms, and the visual pathway, the central nervous system, muscle, heart, pancreatic islets, kidney and liver are preferentially affected.

More research is needed to determine clearly the role of cytoplasmic genetic systems in humans and domestic animals. With regard to oxidative phosphorylation, detailed molecular studies are needed to understand the regulation of expression of both nuclear and mitochondrial genes involved in this pathway. Specifically, research should be aimed at understanding mitochondrial biogenesis, the fate of paternal mtDNA in early embryos and the segregation, replication and expression of mtDNA during development and growth of livestock animals. This information will have important implications not only for our understanding of mitochondrial genetics and diseases in humans (Shoffner and Wallace, 1990) but for the increased productivity of animals (Schultz et al., 1993). There will also be ramifications to the animal cloning industry. In the latter case, those undertaking the production of female cloned families should be particularly attentive to the source of oocytes used in the protocol, since mtDNA of the oocyte will be permanently incorporated and transmitted to all female progeny. This may be used as a tool to create 'new' breeds of livestock carrying the best of both nuclear and mitochondrial genes or, as a result of inappropriate crossing, the introduction of mutations or undesirable traits. Moreover, after the identification of mtDNA polymorphisms correlated with performance traits, the appropriate sequences could be transfected into mitochondria. Introduction of these mitochondria into embryos will result in transgenic animals at the mtDNA level which would be useful for pharmaceutical or production purposes. Canada.

The authors would like to thank L. Moquin for technical help and acknowledge the financial support of NSERC.

\section{References}

Alcivar AA and Pineda MH (1990) Differences in type of mitochondrial DNA (mtDNA) between donors and recipients do not affect pregnancy rates after transfer of rat embryos Theriogenology 33 I 85 (Abstract)

Alcivar AA, Hake LE. Millette CF, Trasler JM and Hecht NB (1989) Mitochondrial gene expression in male germ cells of the mouse Developmental Biology 135 263-271

Alcivar AA, Dooley MP, Hecht NH and Pineda MH (1992) Mitochondrial DNA (mtDNA) is unmethylated in both somatic and germinal cells of rats Theriogenology 37186 (Abstract)
Anderson S, Bankier AT, Barrell BG, de Bruijn MHL, Coulson AR, Drouin J, Eperon IC, Nierlich DP, Roe BA, Sanger F, Scheier PH, Smith AJH, Staden F and Young IG (1981) Sequence and organization of the human mitochondrial genome Nature 290 457-465

Anderson S, Bankier AT, Barrell BG, de Bruijn MHL, Coulson AR, Drouin J, Eperon IC, Nierlich DP, Roe BA, Sanger F, Scheier PH, Smith AJH, Staden R and Young IG (1982a) In Milochondrial Genes pp 5-43 Eds P Slonimski, P Borst and G Attardi. Cold Spring Harbor, New York 
Anderson S, de Bruijn MHL. Coulson AR, Eperon IC, Sanger F and Young IG (1982b) The complete sequence of bovine mitochondrial DNA: conserved features of the mammalian mitochondrial genome Joumal of Molecular Biology 156 683-717

Anderson WA and Perotti ME (1975) An ultracytochemical study of the respiratory potency, integrity, and fate of the sea urchin sperm mitochondria during early embryogenesis Joumal of Cell Biology 66 367-376

Bahr GF and Engter WF (1970) Consideration of volume, mass. DNA and arrangement of mitochondria in midpiece of bull spermatozoa Experimental Cell Research 60 338-340

Beerman F and Hansmann I (1986) Follicular maturation, luteinization, and first meiotic division in oocytes after inhibiting mitochondrial function in mice with chloramphenicol Mutation Research 160 47-54

Bell BR, McDaniel BT and Robinson OW (1985) Effects of cytoplasmic inheritance on production traits in dairy cattle Joumal of Dairy Science 68 2038-2051

Bibb NH, Van Etten RA, Wright CT, Walberg MW and Clayton DA (1981) Sequence and gene organization of mouse mitochondrial DNA Cell 26 167-180

Boursot P. Yonekawa $H$ and Bonhomme F (1987) Heteroplasmy in mice with deletion of a large coding region of mitochondria DNA Molecular Biology and Evolution 4 46-55

Brothers A] (1976) Stable nuclear activation dependent on a. protein synthesised during oogenesis Nalure 260 112-115

Campbell MD, Neymark MA, Hill PK, Rothkopf MM and Dimino MJ (1980) Biochemical and structural differences between porcine ovarian follicular and luteal mitochondria Biology of Reproduction $23231-235$

Cran DG (1985) Qualitative and quantitative structural changes during pig oocyte maturation Journal of Reproduction and Ferfility 74 237-245

DeMartino CA. Floride A, Marcante ML. Malorni W, ScorzaBarcellona P, Bellocci M and Silvestrini B (1979) Morphological, histochemical, and biochemical studies on germ cell mitochondria of normal rats Cell and Tissue Research 196 $1-22$

Dzapo V and Wassmuth R (1983) Mitochondrialer Stoffwechsel und heterotische Effekte beim Schwein. Ergebnisse eines reziproken Kreuzungsversuches. Il. Atmungsaktivitat und oxydative phosphorylierung in Herz-, Leber-, und Hodenmitochondrien Zeitschnift fur Tierzuchtang und Zuchtungsbiologie 100 280-295

Dzapo V and Wassmuth R (1984) Mitochondrialer Stoffwechsel und heterotische Effekte beim Schwein. Ergebnisse eines reziproken Kreuzungsversuches. IIl. Die Aktivitaten der enzyme der Atmungskette in Leber-, Hoden-, und Herzmitochondrien Zeitschrift fur Tierzuchtang und Zuchhungsbiologie 101 112-130

Dzapo V, Schnarr W and Wassmuth R (1983) Mitochondrialer Stoffwechsel und heterotiche Effekte beim Schwein. Ergebnisse eines reziproken Kreuzungsversuches. I. Reproduktionsleistung, wachstumsintensitat und Schlachtkorperqualitat Zeitschrift fur Tierzuchtang und Zuchtungsbiologie 100 109-122

Ebert KM, Alcivar A, Liem H, Goggins R and Hecht NB (1989) Mouse zygote injected with mitochondria develop normally but the exogenous mitochondria are not detectable in the progeny Molecular Reproduction and Development 1 $156-163$

Fisher-Lindahl K and Burki K (1982) Mta, a matemally inherited cell surface antigen of the mouse, is transmitted in the egg
Proceedings of the National Academy of Sciences USA 79 5362-5366

Freeman AE and Beitz DC (1992) Cytoplasmic inheritance molecular differences and phenotypic expression. In Procedings of the Symposium on Cloning Mammals by Nuclear Transplantation, PP 17-20 Ed. GE Seidel, Jr. Colorado State University Press, Fort Collins, $\mathrm{CO}$

Gadaleta G. Pepe G, De Candia G, Quadriariello C. Sbisà E and Saccone C (1989) The complete nucleotide sequence of the Ratius noroegicus mitochondrial genome: cryptic signals revealed by comparative analysis between vertebrates Jounal of Molecular Evolution 28 497-516

Giles RE, Blanc H, Cann HM and Wallace DC (1980) Matemal inheritance of human mitochondrial DNA Proceedings of the National Academy of Sciences USA 77 6715-6719

Gray MW (1992) The endosymbiotic hypothesis revisited International Review of Cylology 141 233-238

Gyllensten U, Wharton D and Wilson AC (1985) Matemal inheritance of mitochondrial DNA during backerossing of two species of mice Joumal of Heredity 76 321-324

Gyllensten U, Wharton D, Josefsson A and Wilson AC (1991) Paternal inheritance of mitochondrial DNA in mice Nature 352 255-257

Hauswirth WW and Laipis PJ (1985) Transmission genetics of mammalian mitochondria: a molecular model and experimental evidence. In Achievements and Perspectives of Mito. chondial Research pp 49-59 Eds E Quaglitiero, EC Slater, F Palmieri, C Saccone and A Kroon. Elsevier Science Publishers, Italy

Hayashi Jl, Tagashira Y, Yoshida MC, Ajiro K and Sekiguchi T (1983) Two distinct types of mitochondrial DNA segregation in mouse-rat hybrid cells Experimental Cell Research $14751-61$

Hecht NB, Liem H, Kleene KC, Distel RJ and Ho S-M (1984) Maternal inheritance of the mouse mitochondrial genome is not mediated by a loss or gross alteration of the paternal mitochondrial DNA or by methylation of the oocyte mitochondrial DNA Developmental Biology 102 $452-461$

Hecht $W(1990)$ Studies on mitochondrial DNA in farm animals. In Genome Antalysis in Domestic Animals pp 259-267 Eds H Geldermann and S Ellendorff. Weinhein. New York

Hiendleder S. Hecht W and Wassmuth R (1991) Characterization of ovine mitochondrial DNA D-loop sequences and possible association of polymorphisms with phenotypic traits Animal Genetics 22 (Supplement 1) 68 (Abstract)

Hiraoka J-I and Hirao Y-H (1988) Fate of sperm tail components after incorporation into the hamster egg Gamete Research 19 369-380

Huizinga HA, Korver S. McDaniel BT and Politiek RD (1986) Maternal effects due to cytoplasmic inheritance in dairy cattle. Influence on milk production and reproduction traits Livestock Production Science 15 11-26

Hutchinson CA, III, Newbold JE, Potter SS and Edgell MH (1974) Maternal inheritance of mammalian mitochondrial DNA Nature 251 536-538

Hyttel P, Callensen $\mathbf{H}$ and Greve T (1986) Ultrastructure features of preovulatory oocyte maturation in superovulated cattle joumal of Reproduction and Fertility 76 645-656

Krause WJ, Charlson EJ, Sherman DM and Day BN (1992) Three-dimensional reconstruction using a computer graphics system: application to mitochondrial aggregates in porcine oocytes, zygotes, and early embryos using a personal computer Zoologischer Anzeiger 229 2 I-36 
Kruip TA, Cran DC, VanBeneden TH and Dieleman SJ (1983) Structural changes in bovine oocytes during final maturation in vivo Gamete Research 8 29-48

Michaels CS, Hauswirth WW and Laipis PJ (1982) Mitochondrial DNA copy number in bovine oocytes and somatic cells Developmental Biology 94 246-251

Muggleton-Harris AL and Brown JJG (1988) Cytoplasmic factors influence mitochondrial reorganization and resumption of cleavage during culture of early mouse embryos Human Reproduction 3 1020-1028

Piko $L$ and Matsumoto L (1976) Number of mitochondria and some properties of mitochondrial DNA in mouse eggs Developmental Biology 49 1-10

Piko $\mathrm{L}$ and Taylor KD (1987) Amounts of mitochondrial DNA and abundance of some mitochondrial gene transcripts in early mouse embryos Developmental Biology 123 364-374

Plante Y. Schmutz SM and Lang KDM (1992) Restriction fragment length polymorphism in the mitochondrial DNA of cloned cattle Theriogenology 38 897-904

Ron M, Cenis I, Ezra E, Yoffe O, Weller Jl and Shani M (1992) Mitochondrial DNA polymophism and determination of effects on economic traits in dairy cattle Animal Biotechnology 3 201-219

Rowe $M$ and Bremm J (1989) Theca cells are more luteal-like than granulosa cells regarding expression of mitochondrial genes FASEB Jounal 73 3721-3729

Rowe MJ, Bieszezad RR, Neymark MA and Dimino MJ (1981) Synthesis of mitochondrial proteins after stimulation of ovarian follicle by lukeinizing hormone Endocrinology 108 127-132

Sager $R$ and Grabowy C (1983) Differential methylation of chloroplast DNA regulates maternal inheritance in a methylated mutant of Chlamydomonas Proceedings of the National Academy of Sriences USA 80 3025-3029

Schultz MM, Freeman AE, Beitz DC and Mayfield JE (1992) The importance of matemal lineages on milk production of dairy cattle journal of Dairy Science 75 1331-1338

Schultz MM. Freeman AE, Lindberg GL and Beitz DC (1993) Effects of matemal lineages group by mitochondrial genotypes on milk yield and composition Jountal of Dairy Science 76 621-629

Shoffner JM and Wallace DC (1990) Oxidative phosphorylation diseases: disorders of two genomes Adoances in Human Genetics 19 267-330

Shuster RC. Rubenstein AJ and Wallace DC (1988) Mitochondrial DNA in anucleate human blood cells Biochemical and Biopliysical Research Communications 155 1360-1365

Smith LC. Silversides DW and Alcivar AA (1991) The development of reconstituted mouse zygotes with mitochondria of mixed origin Jounul of Reproduction and Fertility Abstract Series 8 Abstract 17
Smith LC, Silversides DW and Alcivar AA (1992) Distribution of mitochondria in heteroplasmic mice derived by embryo reconstitution. In The Developmental Basis of Inherited Disorders P 14 (Abstract) Proceedings of the British Society for Developmental Biology Kingston Polytechnic, London

Solter D, Aronson J, Gilbert SF and McGrath J (1985) Nuclear transfer in mouse embryos: activation of the embryonic genome Cold Spring Harbor Symposium on Quantitative Biology 50 45-50

Stern S. Biggers JD and Anderson E (197I) Mitochondria and early development of the mouse Journal of Experimental Morphology 176 179-192

Szöllösi D (1965) The fate of sperm middle piece mitochondria in the rat Jounal of Experimental Morphology 159 367-378

Szöllösi D (1972) Changes in some organelles during oogenesis in mammals. In Oogenesis pp 47-64 Ed. JD Biggers. University Park Press, New York

Upholt WB and Dawid IB (1977) Mapping of mitochondrial DNA in individual sheep and goats: rapid evolution in the D-loop origin Cell 11 571-583

Van Blerkom J and Runner MN (1984) Mitochondria reorganization during resumption of arrested meiosis in the mouse oocyte American Joumal of Anatomy 171 335-355

Vaughn KC, DeBonte LR, Wilson KG and Schaffer GW (1980) Organelle alteration as a mechanism for matemal inheritance Science 208 196-198

Wallace DC (1992) Diseases of the mitochondrial DNA Amual Revietos of Biochemistry 61 1175-1212

Wassarman PM and Josefowicz WJ (1978) Oocyle development in the mouse: an ultrastructural comparison of oocytes at various stages of growth and meiotic competence jounul of Morphology 156 209-236

Watanabe T, Dewey H and Mintz B (1978) Teratocarcinoma cells as vehicles for introducing specific mutant mitochondrial genes into mice Proceedings of the National Academy of Sciences USA 75 5113-5117

Watanabe T, Hayashi $Y$, Ogasawara $N$ and Tomoita T (1985) Polymorphism of mitochondrial DNA in pigs based on restriction endonuclease cleavage patterns Biochemical Genetics 23 105-113

Watanabe T, Hayashi Y, Kimura J, Yasuda Y, Saitou N. Tomita T and Ogasawara $N$ (1986) Pig mitochondrial DNA: poly. morphism, restriction map orientation, and sequence data Biochemical Genetics 24 385-396

Zouros E, Freeman KR, Ball AO and Pogson GH (1992) Direct evidence for extensive patemal mitochondrial DNA inheri. tance in the marine mussel Mytilus Nature 359 412-414 